ARGIPA. 2020. Vol. 5, No.1: 11-17

Available online: https://journal.uhamka.ac.id/index.php/argipa

p-ISSN 2502-2938; e-ISSN 2579-888X

DOI 10.22236/argipa.v5i1.3891

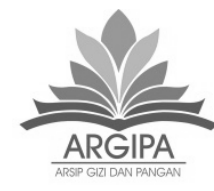

\title{
PENGARUH PEMBERIAN SMOOTHIES BELIMA TERHADAP TEKANAN DARAH SISTOLIK DAN DIASTOLIK PESERTA POSBINDU CIKOKOL KOTA TANGERANG
}

\author{
Effect of Belima smoothies on systolic and diastolic blood pressure of Posbindu Cikokol \\ participants in Tangerang City
}

\section{Sofia Harnum}

Program Studi Ilmu Gizi, Fakultas Ilmu-ilmu Kesehatan, Universitas Muhammadiyah Prof. DR. Hamka, Jakarta Email korespondensi: sofiaharnum@gmail.com

\begin{abstract}
ABSTRAK
Penderita hipertensi akan menjalani hidup dengan bergantung pada obat-obatan yang sering menimbulkan efek samping. Penelitian ini memberikan alternatif dalam mengatasi hipertensi menggunakan bahan-bahan alami untuk meminimalisasi efek samping yaitu dengan pemberian smoothies belima (belimbing, pisang, kayu manis, dan buah naga) yang mengandung serat dan kalium sebanyak $250 \mathrm{ml}$. Jenis penelitian ini yaitu eksperimental dengan rancangan one group pre-test post-test. Metode penelitian ini menggunakan metode total sampling. Tujuan penelitian ini untuk mengetahui perbedaan tekanan darah sistolik dan diastolik dengan adanya pemberian smoothies belima pada peserta Posbindu Cikokol Kota Tangerang. Subjek pada penelitian ini sebanyak 32 orang. Data dianalisis dengan uji Paired $t$ test dan uji Wilcoxon. Terdapat perbedaan yang signifikan antara sebelum dan sesudah diberikan smoothies belima. Rata-rata tekanan darah sistolik turun setelah intervensi dari 143 $\mathrm{mmHg}$ menjadi $127 \mathrm{mmHg}$. Tekanan darah diastolik dengan nilai rata-rata sebelum intervensi $90 \mathrm{mmHg}$ menjadi $80 \mathrm{mmHg}$. Asupan natrium turun dari $4.825 \mathrm{mg}$ menjadi $2.881,2 \mathrm{mg}$, asupan kalium naik dari 1.020,8 mg menjadi $1.625,4 \mathrm{mg}$, dan asupan serat dengan nilai ratarata sebelum intervensi 7,2 g naik menjadi 11,6 $\mathrm{g}$.
\end{abstract}

Kata kunci: Belimbing, Buah Naga, Kayu Manis, Pisang, Tekanan Darah Tinggi

\begin{abstract}
Patients with hypertension will live life, depend on drugs that often cause side effects. This research provides an alternative in overcoming hypertension using natural ingredients to minimize side effects, namely by giving belima smoothies (star fruit, banana, cinnamon, and dragon fruit) containing $250 \mathrm{ml}$ of fiber and potassium. This type of research is experimental with one group pre-test post-test design. This research method uses the total sampling method. This study's purpose was to determine the differences in systolic and diastolic blood pressure on the administration of belima smoothies to participants in Posbindu Cikokol Tangerang City. The subjects in this study were 32. Data were analyzed by the Paired t-test and Wilcoxon test. There were significant differences between before and after Belima smoothies intervention. The rate of systolic blood pressure was lower from $143 \mathrm{mmHg}$ to $127 \mathrm{mmHg}$. The rate of diastolic blood pressure was lower from $90 \mathrm{mmHg}$ to $80 \mathrm{mmHg}$. Sodium intake was lower from 4,825 $\mathrm{mg}$ to 2,881.2 $\mathrm{mg}$, potassium intake increases from 1,020.8 $\mathrm{mg}$ to 1,625, $4 \mathrm{mg}$ and fiber intake also increase from $7.2 \mathrm{~g}$ to $11.6 \mathrm{~g}$.
\end{abstract}

Keywords: Banana, Cinnamon, Dragon Fruit, High Blood Pressure, Star fruit 


\section{PENDAHULUAN}

Hipertensi berkaitan dengan tekanan darah sistolik dan diastolik. Tekanan darah sistolik adalah tekanan pada saat otot ventrikel jantung berkontraksi. Tekanan darah diastolik adalah tekanan pada saat otot atrium jantung berkontraksi dan darah menuju ventrikel. Pada kondisi hipertensi, tekanan darah sistolik lebih dari sama dengan $120 \mathrm{mmHg}$ dan tekanan darah diastolik lebih dari $80 \mathrm{mmHg}$ (Whelton, et al., 2017).

Hipertensi merupakan penyebab kematian nomor 3 setelah strok dan tuberkulosis yang proporsi kematiannya mencapai $6,7 \%$ dari populasi kematian pada semua umur di Indonesia (Lingkungan, 2010). Prevalensi hipertensi untuk kelompok umur $\geq 18$ tahun meningkat yaitu sebesar 8,3\% dari tahun 2013 sampai 2015 (Balitbangkes, 2018). Penderita hipertensi di Indonesia diperkirakan sebesar 15 juta, tetapi hanya 4\% yang hipertensinya terkendali. Sebaliknya sebesar $50 \%$ penderita tidak menyadari sebagai penderita hipertensi sehingga mereka cenderung untuk menderita hipertensi yang lebih berat (Tarigan, et al., 2018).

Sebagian kasus hipertensi penyebabnya tidak diketahui, namun ada beberapa faktor yang dapat meningkatkan risiko terkena hipertensi di antaranya kelebihan berat badan, kurang berolah raga, banyak mengonsumsi makanan berkadar natrium tinggi, kurang mengonsumsi sayuran, dan terlalu banyak minum alkohol (Noerhadi, 2008).

Berdasarkan penelitian Dietary Approaches to Stop Hypertention (DASH) dikatakan untuk menurunkan tekanan darah sangat dianjurkan untuk mengonsumsi makanan yang kaya akan nutrisi seperti kalium dan serat (National Institutes of Health, 2006).

Rata-rata asupan kalium yang dianjurkan dalam sehari yaitu sebesar $4700 \mathrm{mg}$, asupan serat sebesar $30 \mathrm{~g}$, dan asupan natirum $1300 \mathrm{mg}$ (WNPG, 2013). Konsumsi natrium perlu diimbangi dengan konsumsi kalium. Rasio Na:K <1 diperkirakan dapat menurunkan sekitar 3,4 mmHg tekanan darah. Rasio konsumsi kalium dan natrium yang baik adalah 1:1. Subjek dengan rasio kalium natrium yang kurang mempunyai risiko 5,8 kali terkena hipertensi dibandingkan dengan subjek yang rasio konsumsi kalium natriumnya baik (Atun, et al., 2014).

Sebelumnya, penelitian yang bertujuan menurunkan tekanan darah telah dilakukan. Penelitian yang dilakukan Alvionita (2018) menunjukkan perbedaan efektivitas sebelum dan sesudah diberikan jus belimbing terhadap penurunan tekanan darah tinggi pada penderita hipertensi di Posbindu Puskesmas Bendo. Pemberian jus buah bit selama 7 hari berturut-turut juga diketahui berhasil menurunkan tekanan darah (Nandani \& Sofyaningsih, 2019).

Peneliti mencari alternatif yaitu menyatukan bahan-bahan yang kaya 
akan kalium dan serat tersebut menjadi smoothies belima yang bertujuan untuk menurunkan tekanan darah sebagai salah satu terapi nonfarmakologis. Smoothies belima merupakan campuran yang terdiri dari belimbing, pisang, kayu manis, dan buah naga. Minuman ini diharapkan dapat menjadi sebuah terobosan dalam mengatasi permasalahan hipertensi dengan pengaplikasian yang mudah dan bahan-bahan yang mudah dijangkau. Penelitian ini dilakukan di Posbindu Cikokol Kota Tangerang selama 7 hari beturut-turut dengan pemberian $250 \mathrm{ml}$ smoothies belima.

Tujuan dari penelitian ini yaitu untuk mengetahui perbedaan tekanan darah sistolik dan diastolic dengan adanya pemberian smoothies belima pada peserta Posbindu Cikokol.

\section{METODE}

Penelitian ini termasuk dalam penelitian eksperimental dengan menggunakan desain penelitian one group pre-test post-test. Penelitian ini dilakukan di Posbindu Cikokol Kota Tangerang pada bulan September 2019. Subjek pada penelitian ini sebanyak 32 orang dengan menggunakan total sampling.

Pada awal penelitian dilakukan skrining untuk mendapatkan subjek dengan kriteria tekanan darah $\geq 120 / 80$ mmHg, bersedia menjadi subjek penelitian selama 7 hari, tidak sedang menjalani pengobatan atau mengonsumsi obat antihipertensi, dan tidak memiliki alergi terhadap belimbing, pisang, kayu manis, dan buah naga.
Seluruh subjek yang memenuhi kriteria masuk ke dalam kelompok intervensi. Setelah subjek didapat dilakukan intervensi selama 7 hari berturut-turut. Saat intervensi berlangsung, subjek diukur tekanan darahnya sebanyak 14 kali, yaitu 7 kali sebelum intervensi pada saat subjek dalam keadaan istirahat dan 7 kali setelah intervensi. Setelah dilakukan pengambilan tekanan darah awal, peneliti memberikan smoothies belima sebanyak $250 \mathrm{ml}$ dan melakukan pemeriksaan tekanan darah kembali oleh enumerator setelah 30 menit subjek menghabiskan smoothies belima.

Pada penelitian ini dilakukan wawancara menggunakan food recall 24 jam sebanyak 2 kali yaitu saat hari pertama dan hari terakhir penelitian untuk mendapatkan asupan sebelum dan sesudah penelitian. Asupan makan yang diperhatikan yaitu asupan kalium, serat, dan natrium.

Setelah dilakukan uji normalitas, dilakukan uji perbedaan dengan menggunakan uji Paired t-test (asupan natrium) dan uji Wilcoxon (tekanan darah sistolik dan diastolik, asupan kalium, dan asupan serat) untuk mengetahui perbedaan tekanan darah sistolik dan diastolik, asupan natrium, asupan kalium, dan asupan serat sebelum dan sesudah diberikan smoothies belima. Penelitian ini telah mendapat persetujuan etik oleh Komisi Etik Universitas Muhammadiyah Prof. DR. Hamka dengan nomor register No.03/19.08/0134. 
HASIL

Subjek pada penelitian ini didominasi subjek yang memiliki usia $\geq 45$ tahun $(71,9 \%)$ dan berjenis kelamin wanita (75\%). Hal ini dikarenakan peserta Posbindu Cikokol didominasi oleh ibu rumah tangga (Tabel 1).

Tabel 1.

Gambaran distribusi subjek berdasarkan usia dan jenis kelamin

\begin{tabular}{lcc}
\hline Variabel & $\mathbf{n}$ & $\mathbf{0}$ \\
\hline Usia & & \\
Usia $<45$ tahun & 9 & 28,1 \\
Usia $\geq 45$ tahun & 23 & 71,9 \\
\hline Jenis Kelamin & & \\
Pria & 8 & 25 \\
Wanita & 24 & 75 \\
\hline Total & $\mathbf{3 2}$ & $\mathbf{1 0 0}$ \\
\hline
\end{tabular}

Tekanan darah sistolik sebelum diberikan intervensi yaitu $140 \mathrm{mmHg}$ dan menurun setelah diberikan intervensi menjadi $130 \mathrm{mmHg}$. Terdapat perbedaan yang signifikan antara nilai tekanan darah sistolik sebelum dan sesudah diberikan smoothies belima $(p<0,005)$ (Tabel 2$)$. Hasil tekanan darah diastolik sebelum diberikan intervensi yaitu $90 \mathrm{mmHg}$ dan menurun setelah diberikan intervensi menjadi $80 \mathrm{mmHg}$.
Terdapat perbedaan yang signifikan antara nilai tekanan darah diastolik sebelum dan sesudah diberikan smoothies belima $(p<0,005)$ (Tabel 2).

Asupan kalium sebelum diberikan intervensi yaitu 939,9 mg dan meningkat setelah diberikan intervensi menjadi $1.576 \mathrm{mg}$. Dengan demikian terdapat perbedaan yang signifikan antara nilai asupan kalium sebelum dan sesudah diberikan smoothies belima $(p<0,005)$ (Tabel 2$)$.

Tabel 2.

Hasil uji statistik variabel terhadap pemberian smoothies belima

\begin{tabular}{lcc}
\hline \multicolumn{1}{c}{ Variabel } & Median (Min-Max) & $p$ \\
\hline Tekanan Darah Sistolik & $140(130-170)$ & 0,000 \\
Sebelum & $130(110-150)$ & \\
Sesudah & & \\
Tekanan Darah Diastolik & $90(80-100)$ & 0,000 \\
Sebelum & $80(70-90)$ & \\
Sesudah & & 0,000 \\
Asupan Kalium & $939,9(476-2222)$ & \\
Sebelum & $1.576(144,8-3119,2)$ & 0,000 \\
Sesudah & $6,3(2,4-25,5)$ & \\
Asupan Serat & $10,3(4,7-22)$ &
\end{tabular}


Tabel 3.

Hasil uji statistik asupan natrium terhadap pemberian smoothies belima

\begin{tabular}{lcccc}
\hline Variabel & Mean (s.d) & Selisih (s.d) & IK 95\% & $p$ \\
\hline $\begin{array}{l}\text { Asupan Natrium Sebelum } \\
\text { Perlakuan }\end{array}$ & $4.825(1.257,5)$ & $1944,1(1.771,5)$ & $1.305,3-2.582,8$ & 0,000 \\
\hline $\begin{array}{l}\text { Asupan Natrium Sesudah } \\
\text { Perlakuan }\end{array}$ & $2.881,2(974,5)$ & & & \\
\hline
\end{tabular}

Asupan serat sebelum intervensi yaitu 6,3 gram dan meningkat setelah diberikan intervensi menjadi 10,3 gram. Terdapat perbedaan yang signifikan antara nilai asupan serat sebelum dan sesudah diberikan smoothies belima $(p<0,005)$ (Tabel 2).

Nilai rata-rata asupan natrium sebelum intervensi yaitu $4.825 \mathrm{mg}$ dan menurun setelah diberikan intervensi menjadi 2.881,2 mg. Jadi, terdapat perbedaan yang signifikan antara nilai asupan natrium sebelum dan sesudah diberikan smoothies belima $(p<0,005)$ (Tabel 3).

\section{DISKUSI}

Hasil penelitian ini menyatakan bahwa terdapat perbedaan yang signifikan antara tekanan darah sistolik dan diastolik, asupan natrium, asupan kalium, dan asupan serat sebelum dan sesudah diberikan smoothies belima.

Dalam $250 \mathrm{ml}$ smoothies belima mengandung 385,8 mg kalium, 4 gram serat, dan 0,004 gram natrium sehingga termasuk dalam sumber kalium serat dan bebas natrium berdasarkan klaim kandungan zat gizi dalam peraturan Kepala Badan Pengawas Obat dan Makanan Nomor 13 tahun 2016.
Menurut Astawan (2002) kalium menurunkan sekresi hormon antidiuretik $(\mathrm{ADH})$ dan rasa haus. $\mathrm{ADH}$ diproduksi di hipotalamus (kelenjar pituitari) dan bekerja pada ginjal untuk mengatur osmolalitas dan volume urin, dengan menurunnya $\mathrm{ADH}$, akan banyak urin yang disekresikan keluar tubuh (antidiuresis). Karena itu, smoothies belima memiliki peran dalam menurunkan tekanan darah karena mengandung kalium dan serat di dalamnya.

Asupan natrium yang tinggi dapat menjadi salah satu faktor terjadinya hipertensi. Hal ini sejalan dengan penelitian Susanti (2017), konsumsi natrium yang tinggi dapat mengecilkan diameter dari arteri sehingga jantung harus memompa lebih keras dan menyebabkan tekanan darah meningkat. Subjek dengan konsumsi natrium yang tinggi memiliki risiko 5,7 kali terkena hipertensi dibandingkan dengan subjek yang mengonsumsi natrium cukup (Atun, et al., 2014). Pada penelitian ini, subjek memiliki asupan natrium melebihi kebutuhan dalam sehari. Penurunan asupan natrium subjek disebabkan oleh kesadaran subjek dalam pengurangan asupan 
natrium dan meningkatkan asupan kalium dan serat yang bersumber dari smoothies belima.

Pada penelitian ini asupan kalium dan serat subjek di bawah batas kebutuhan dalam sehari. Hal ini dikarenakan pemilihan bahan makanan yang kurang beragam. Salah satu di antaranya adalah rendahnya asupan sayur dan buah dalam sehari. Hal ini menjadi salah satu faktor penyebab terjadinya hipertensi karena sayur dan buah merupakan sumber kalium dan serat yang dapat membantu mencegah terjadinya hipertensi. Cara kerja kalium kebalikan dari natrium, banyak mengonsumsi kalium akan meningkatkan konsen-trasi di dalam cairan intraselular dan menaikkan cairan ekstraselular sehingga dapat menurunkan tekanan darah.

Asupan serat yang rendah dapat menyebabkan obesitas yang penderitanya cenderung mengonsumsi makanan tinggi lemak yang lebih mudah dicerna dibandingkan serat. Asupan serat dapat membantu meningkatkan pengeluaran kolesterol melalui feses dengan jalan meningkatkan waktu transit bahan makanan melalui usus. Mengonsumsi serat sangat menguntungkan karena dapat mengurangi pemasukan energi dan obesitas yang pada akhirnya menurunkan risiko penyakit tekanan darah tinggi (Baliwati, et al., 2004).

\section{SIMPULAN}

Smoothies belima dapat menjadi salah satu alternatif dalam mencegah dan menurunkan tekanan darah tinggi karena merupakan minuman sumber kalium dan serat.

\section{UCAPAN TERIMA KASIH}

Penulis mengucapkan terima kasih kepada UHAMKA, Dinas Kesehatan Kota Tangerang, dan Puskesmas Cikokol Kota Tangerang.

\section{DAFTAR RUJUKAN}

Alvionita, M. J. (2018). Perbedaan Efektivitas antara Pemberian Jus Belimbing Manis dan Jus Wortel terhadap Penurunan Tekanan Darah pada Penderita Hipertensi di Posbindu Desa Pingkuk Wilayah Kerja Puskesmas Bendo Kabupaten Magetan. Skripsi. Madiun: STIKES Bakti Husada Mulia.

Astawan, M. (2002). Cegah Hipertensi dengan Pola Makan. Jakarta: PT Gramedia Pusaka Utama.

Atun, L., Siswati, T., \& Kurdanti, W. (2014). Asupan sumber natrium, rasio kalium natrium, aktivitas fisik, dan tekanan darah pasien hipertensi. Media Gizi Mikro Indonesia, 6(1), 63-71.

Balitbangkes. (2018). Hasil Utama Riset Kesehatan Dasar (RISKESDAS). In Kementrian Kesehatan RI. https://doi.org/10.1088/17518113/44/8/085201

Baliwati, Y. F., Khomsan, A., Dwiriani, C. M. (2004). Pengantar Pangan dan Gizi. Jakarta: Penebar Swadaya.

Lingkungan, I. D. K. D. P. P. d. P. (2010). Pedoman Teknis Penemuan dan Tatalaksana Penyakit Hipertensi. Jakarta: Direktorat Pengendalian Penyakit Tidak Menular Ditjen. PP dan PL Depkes. 
Nandani, A. D., \& Sofyaningsih, M. (2019). The effect of beet juice consuming to the tension of hypertension patients. ARGIPA (Arsip Gizi Dan Pangan), 4(1), 1-10. https:// doi.org/10.22236/argipa.v $4 \mathrm{i} 1.3787$

National Institutes of Health. (2006). Your Guide to Lowering Your Blood Presure with DASH. U.S Department of Health and Human Science.

Noerhadi, M. (2008). Hipertensi dan pengaruhnya terhadap organorgan tubuh. Medikora, 4(2), 1-18.

Susanti, M. (2017). Hubungan Asupan Natrium dan Kalium dengan Tekanan Darah pada Lansia di Kelurahan Pajang. Skripsi. Surakarta: Fakultas Ilmu Kesehatan Universitas Muhammadiyah Surakarta.
Tarigan, A., Lubis, Z., \& Syarifah, S. (2018). Pengaruh pengetahuan, sikap dan dukungan keluarga terhadap diet hipertensi di Desa Hulu Kecamatan Pancur Batu Tahun 2016. Jurnal Kesehatan, 11, 9-17.

Whelton, PK., Carey, RM., Aronow, WS., Casey, DE., Collins, KJ., Himmelfarb, CD., et al. (2017). 2017 ACC/AHA/ AAPA/ABC/ACPM/AGS/APhA / ASH/ASPC/NMA/PCNA guideline for the prevention, detection, evaluation and management of high blood pressure in adults. J Am Coll Cardiol, [E-pub ahead of print]. 2017 Nov 7.

WNPG. (2013). Angka Kecukupan Gizi (AKG). https://wnpg.lipi.go.id. Diakses 30 Oktober 2019. 